\title{
The effect of body mass index and its interaction with family history on hypertension: a case-control study
}

\author{
An-le Li* ${ }^{*}$, Qian Peng, Yue-qin Shao, Xiang Fang and Yi-ying Zhang
}

\begin{abstract}
Background: BMI is an indicator commonly used in the world to measure the weight and height of the body, it reflects the comprehensive outcome of acquired lifestyle; FH is a sign reflecting the main role of genetic factors. This study aimed to evaluate the effect of BMI and interaction with $\mathrm{FH}$ on hypertension risk in Shanghai adult population.

Methods: According to l:I matched pairs design, 342 cases and 342 controls were selected and investigated in this study, this study was performed in Shanghai, China. Participants received face-to-face questionnaire survey, anthropometric tests and laboratory examinations. Relevant indicators that reflect obesity including BMI and waist to hip ratio (WHR) were calculated. Multivariate logistic regression analysis was applied to explore the association between factors and hypertension risk. Interactive effect was evaluated by synergy index (SI), relative excess risk due to interaction (RERI), attributable proportion due to interaction (AP) and the percentage of the interaction between the pure factors (PAP).

Results: Among 684 study participants aged 28-87 years old, the differences of mean age and height between case group and control group are no significant $(p>0.05)$, but the differences of mean of weight, WC, HC, BMI and WHR are significant $(p<0.001)$. The OR of FH on hypertension is 4.986 (95\% Cl: $2.832 \sim 8.877)$; the OR of BMl on hypertension is respectively: low weight is 1.528 (95\%Cl: $0.551 \sim 4.239$ ), overweight is 3.333 ( $95 \% \mathrm{Cl}: 1.678 \sim 6.617$ ) and obesity is 7.312 (95\%Cl: 3.556 15.035). The OR of interaction between FH and BMI to hypertension is 12.993 (95\%Cl: 7.426 22.734). Sl is 1.90 (95\% Cl: 1.48 3.78), RERl is 5.67 (95\% Cl: 1.66 11.88), AP is 43.87\% (95\% Cl: 12.84 91.88\%), and PAP is 47.55\% (95\%Cl: 13.91 99.58\%). FH and BMI have positive interaction on hypertension. $43.87 \%$ of hypertension exposed to both $\mathrm{FH}$ and BMI was attributable to the interaction of them.

Conclusions: $\mathrm{FH}$ and $\mathrm{BMI}$ are significant higher risks of hypertension; with the increase of BMl, the risk of hypertension will increase more. FH and BMl have positive interaction with hypertension, the interaction is greater than the sum of two independent actions.
\end{abstract}

Keywords: Hypertension, Case-control study, Body mass index, Family history, Interaction

\section{Introduction}

Some epidemiological studies showed that the prevalence of hypertension has significantly increased among children and adolescents in recent years, and hypertension have affected 20 to $30 \%$ of the population worldwide [1-3]. As is known to all, hypertension is a multifactorial disease caused by genetic and environmental factors, the role of gene and gene, as well as between gene and environment, leads to increased risk of hypertension and disease among different populations. Unhealthy lifestyle such as obesity and lack of

\footnotetext{
* Correspondence: anle_li@aliyun.com

Jiading district center for disease control and prevention, Shanghai, China
}

exercise can significantly raise hypertension $[4,5]$. The result of familial aggregation of hypertension showed that in positive population of parents, the prevalence rate of brothers and sisters in offspring is as high as 20 to $66 \%$, a plurality of twin studies have estimated the possibility of hereditary is over $50 \%$ [6]. It shows that more than half of the blood pressure change can be attributed to the accumulation of genetic effects.

It is assumed that blood pressure is controlled by a large number of genes, and each gene has only a relatively weak effect on blood pressure. Therefore, it is difficult to detect genetic variants that affect blood pressure by traditional 
methods such as candidate gene screening and gene linkage studies. Family history $(\mathrm{FH})$ is an important marker of genetic factors, it is often used as an alternative indicator to study the relationship between genetic factors and diseases [7-10]. Body mass index (BMI) is a comprehensive indicator of the outcome of acquired lifestyle, and closely related to the occurrence of hypertension [11-15]. A review of meta-analytic studies has shown that general obesity is measured by BMI, central and abdominal obesity is measured by anthropometric indictor such as waist circumference or waist-to-hip ratio, and obesity is associated with a risk of hypertension and cardiovascular disease mortality [16].

The aim of this study is to evaluate the effect of BMI and interaction with family history on hypertension risk in Shanghai adult population.

\section{Methods}

\section{Study population}

This case-control study included aged 28 to 87 years old; all participants gave informed consent to participate in the study which was approved by the local ethics committee. All cases are randomly selected from hypertension registry and follow-up management system, they are confirmed by hospital and verified by follow-up in the community, they were able to correctly respond to the investigators for health information of themselves. The inclusion criteria of the cases are that it meets the following three conditions at the same time: 1) diagnosed as essential hypertension patients and had been verified by the community management; 2) residents of the district or Shanghai household registration; 3) formally signed the informed consent and voluntarily participated. And the exclusion criteria of the cases are that it meets any of the following conditions: 1 ) patients with secondary hypertension cannot be excluded; 2) patients with renal insufficiency or psychosis; 3) patients with poor compliance.

According to l: 1 matched pairs design, all controls had no hypertension, and gave informed consent to participate in the study, they were able to correctly respond to the investigators for the health information of themselves. The inclusion criteria of the controls are that it meets the following three conditions at the same time: 1) no blood relationship with the case; 2 ) the same sex and race; 3 ) the same place of residence; 4 ) the same age or age difference less than 5 years old.

Family history refers to at least one or more patients with essential hypertension among their lineal relatives, requiring all patients to be distributed within three generations.

\section{Measurements}

\section{Anthropometric measurements}

Waist circumference (WC) was measured at a level midway between the lower rib margin and the iliac crest.
Hip circumference $(\mathrm{HC})$ was measured at the maximum circumference around the buttocks. WC and $\mathrm{HC}$ were measured with using a flexible measuring tape, the accuracy $\pm 0.5 \mathrm{~cm}$. Height of the participants was measured with portable height measurer, the accuracy $\pm 0.1 \mathrm{~cm}$; and weight was measured with SECA measuring equipment (wearing only light clothing and barefooted), the accuracy $\pm 0.1 \mathrm{~kg}$.

Body mass index $(\mathrm{BMI})=$ body weight $(\mathrm{kg}) /$ height squared $\left(\mathrm{m}^{2}\right)$. BMI classification standard: $\mathrm{BMI}<18.5$ is low weight (thin); BMI between 18.5 23.9 is normal weight; BMI between 24.0 27.9 is overweight; BMI over 28.0 is obesity $[17,18]$. The participants were grouped into the following categories of BMI: low weight (thin), normal weight, overweight and obese. WHR $\leq 0.90$ (male) and $\mathrm{WHR} \leq 0.80$ (female) are normal; WHR $>0.90$ (male) and WHR $>0.80$ (female) are abnormal.

\section{Statistical analysis}

Statistical analyses were performed using the statistical software package (IBM SPSS statistics version 21). When $P$ values $<0.05$, the difference was considered statistically significant. Mean and standard deviation (SD) were used to compute for quantitative variables (age, weight, height, WC, HC, BMI and WHR), and comparisons between groups were performed by t-test. Number (n) and percentage (\%)) were computed for the categorical data, comparisons between groups were performed by the chi-square $\left(x^{2}\right)$ test. Univariate and multivariate logistic regression analyses were conducted for investigated risk factors, odds ratios (OR) and 95\% confidence intervals (CI) were calculated. In multivariate analysis, OR were adjusted by sex.

The additive model was used by cross analysis to calculate the additive interaction effect. The synergistic effect index (SI), relative excess risk due to interaction (RERI), attributable proportion due to interaction (AP) and the percentage of the interaction between the pure factor (PAP) calculation formula are as follows [19]:

$$
\begin{gathered}
S I(A B)=\left[R(A B)-R\left(A^{0} B^{0}\right)\right] /\left[R\left(A B^{0}\right)-R\left(A^{0} B^{0}\right)\right. \\
\left.+R\left(A^{0} B\right)-R\left(A^{0} B^{0}\right)\right] \\
R E R I(A B)=\left[R(A B)-R\left(A B^{0}\right)-R\left(A^{0} B\right)+R\left(A^{0} B^{0}\right] /\right. \\
R\left(A^{0} B^{0} A P(A B)=\left[R(A B)-R\left(A B^{0}\right)-R\left(A^{0} B\right)+R\left(A^{0} B^{0}\right)\right] /\right. \\
R(A B) P A P(A B)=\left[R(A B)-R\left(A B^{0}\right)-R\left(A^{0} B\right)+R\left(A^{0} B^{0}\right)\right] / \\
{\left[R(A B)-R\left(A^{0} B^{0}\right)\right]}
\end{gathered}
$$

(Note: $R(A B)$ is the risk ratio of $A$ and $B$ factor exposed; $R\left(A^{0} B^{O}\right)$ is the risk ratio of $A$ and $B$ factor unexposed; $R\left(A B^{O}\right)$ is the risk ratio of $A$ factor exposed but $B$ factor unexposed, $R\left(A^{0} B\right)$ is the risk ratio of $A$ factor unexposed and $B$ factor exposed) 


\section{Results}

\section{Distribution of participants}

In this study, 342 hypertension cases and 342 control populations were investigated. Table 1 shows the distribution of measurement data of the study population in two groups. Among 684 participants aged 28-87 years old, the difference of mean age and height between case group and control group are no significant $(p>0.05)$, but the difference of mean Weight, WC, HC, BMI and WHR between case group and control group are significant $(p<0.001)$. The mean of BMI, WHR, weight, WC and $\mathrm{HC}$ in case group are significantly higher than that of control group. See Table 1.

Table 2 shows the distribution of categorical data of participant in the study. Among these study participants, $76.17 \%$ participants have family history of hypertension (FH), 23.83\% have not FH. 43.42\% participants are normal weight, $2.49 \%$ are low weight, $40.64 \%$ overweight and $13.45 \%$ obesity. $81.43 \%$ of WHR are abnormal. Sex distribution: $50.73 \%$ male; $49.27 \%$ female. Education level: $30.56 \%$ primary school and below; $61.84 \%$ high school; $7.60 \%$ college and above. Blood type: $61.99 \%$ knew and $38.01 \%$ unknown. Occupation: $68.28 \%$ engaged; $6.29 \%$ freelance and $25.44 \%$ no job. Work or life pressure: $90.79 \%$ no feeling or feel little, 9.21\% feel more. Living environmental noise: $91.81 \%$ no feeling or feel little, $8.19 \%$ feel more. Personal taste: $22.37 \%$ like salty taste and $31.29 \%$ like light taste. Sleeping time: $11.40 \%$ feel inadequate; $88.60 \%$ feel adequate. Sports habit: $18.86 \%$ never exercise and $81.14 \%$ exercise. Drinking behavior: $71.20 \%$ never drink and $28.80 \%$ drink. Smoking behavior: 64.91\% never smoking and 35.09\% smoking.

Between case group and control group, the statistical test results shows that the difference of sex, education, blood type, work and life pressure, living environmental noise, person's taste, sleeping time, sports habit, drinking behavior and smoking behavior is no significant $(p>$ $0.05)$. But the difference of family history (FH), BMI, WHR and occupation between case group and control group is significant $(p<0.05)$.

\section{Effect of risk factors on hypertension}

According to the logistic regression analysis models, after adjustment for sex, the result shows that effect of BMI,WHR, FH and drinking behavior are significant ( $p$ $<0.05)$. But effect of age, education, blood type, occupation, work and life pressure, environmental noise, taste, sleeping time, sports habit and smoking behavior are not significant $(p>0.05)$. See Table 3 .

BMI is an indicator commonly used in the world to measure the weight and height of the body, it reflect the comprehensive outcome of acquired lifestyle; family history is an important marker of genetic factors effect. In order to further evaluate the effect and interaction on hypertension, risk factors of FH and BMI are selected on the next analysis. The interclass correlation coefficient was $0.248(p<0.001)$, the results showed that the reliability coefficient was statistically significant. Multilevel logistic regression analysis is used to analyze the individual effect of $\mathrm{FH}$ and BMI on hypertension, the result shows in Table 4.

Table 4 shows the individual effect of $\mathrm{FH}$ and BMI to hypertension by multilevel logistic regression model analysis, and all results are statistical significant. The OR between $\mathrm{FH}$ and hypertension is 4.986 (95\%CI: 2.832 8.877); the OR between low weight $(\mathrm{BMI}<18.5)$ and hypertension is 1.528 (95\%CI: 0.551 4.239), the OR between overweight (BMI 24.0 27.9) and hypertension is 3.333 (95\%CI: 1.679 6.617), the OR between obesity $(\mathrm{BMI} \geq 28.0)$ and hypertension is 7.312 (95\%CI: 3.556 15.035).

\section{Interaction of $\mathrm{FH}$ and $\mathrm{BMI}$}

Table 5 shows the result of interactive effects analysis. The OR of interaction between $\mathrm{FH}$ and BMI to hypertension is 12.993 (95\%CI: 7.426 22.734). $\mathrm{OR}_{\mathrm{FH}+\mathrm{BMI}}>$ $\mathrm{OR}_{\mathrm{FH}}+\mathrm{OR}_{\mathrm{BMI}}$. It is showed that $\mathrm{FH}$ and $\mathrm{BMI}$ have positive interaction with hypertension. According the result of Table 5, use additive model to calculate the additive interaction effect: the synergistic effect index (SI) of FH and BMI to hypertension is 1.90 (95\% CI: 1.48 3.78), relative excess risk due to interaction (RERI) is 5.67

Table 1 Distribution of measurement variables in participants in two groups

\begin{tabular}{|c|c|c|c|c|c|c|}
\hline & \multicolumn{2}{|c|}{ control group $(n=342)$} & \multicolumn{2}{|c|}{ case group $(n=342)$} & \multirow[t]{2}{*}{$\mathrm{t}$} & \multirow[t]{2}{*}{$p$} \\
\hline & mean & SD & mean & SD & & \\
\hline Age (years) & 61.69 & 10.73 & 62.42 & 10.72 & 0.894 & 0.372 \\
\hline BMI $\left(\mathrm{kg} / \mathrm{m}^{2}\right)$ & 23.46 & 3.18 & 25.52 & 3.50 & 8.032 & $<0.001$ \\
\hline WHR & 0.90 & 0.06 & 0.92 & 0.06 & 4.392 & $<0.001$ \\
\hline Height (cm) & 163.30 & 8.10 & 162.81 & 7.94 & 0.799 & 0.424 \\
\hline Weight (kg) & 62.62 & 10.04 & 67.75 & 11.35 & 6.262 & $<0.001$ \\
\hline WC $(\mathrm{cm})$ & 83.73 & 9.96 & 88.69 & 9.09 & 6.806 & $<0.001$ \\
\hline $\mathrm{HC}(\mathrm{cm})$ & 92.79 & 9.26 & 96.07 & 8.22 & 4.898 & $<0.001$ \\
\hline
\end{tabular}

$B M I$ body mass index, WHR waist-to-hip ratio, WC waist circumference, $H C$ hip circumference 
Table 2 Distribution of categorical variables in participants in two groups (N, \%)

\begin{tabular}{|c|c|c|c|c|c|c|c|}
\hline & & \multicolumn{2}{|c|}{ control group $(n=342)$} & \multicolumn{2}{|c|}{ case group $(n=342)$} & \multirow[b]{2}{*}{$x^{2}$} & \multirow[b]{2}{*}{$p$} \\
\hline & & $\bar{n}$ & $\%$ & $n$ & $\%$ & & \\
\hline \multirow[t]{2}{*}{ sex } & male & 175 & 51.17 & 172 & 50.29 & 0.119 & 0.730 \\
\hline & female & 167 & 48.83 & 170 & 49.71 & & \\
\hline \multirow[t]{5}{*}{ Education level } & Below primary & 20 & 5.85 & 22 & 6.43 & 6.567 & 0.161 \\
\hline & primary school & 84 & 24.56 & 83 & 24.27 & & \\
\hline & junior high & 135 & 39.47 & 152 & 44.44 & & \\
\hline & high school & 69 & 20.18 & 67 & 19.59 & & \\
\hline & $\geq$ college & 34 & 9.94 & 18 & 5.26 & & \\
\hline \multirow[t]{2}{*}{ family history } & no & 131 & 38.30 & 32 & 9.36 & 80.048 & $<0.001$ \\
\hline & yes & 211 & 61.70 & 310 & 90.64 & & \\
\hline \multirow[t]{4}{*}{ body mass index } & low weight & 12 & 3.51 & 5 & 1.46 & 63.165 & $<0.001$ \\
\hline & normal & 194 & 56.73 & 103 & 30.12 & & \\
\hline & overweight & 112 & 32.75 & 166 & 48.54 & & \\
\hline & obesity & 24 & 7.02 & 68 & 19.88 & & \\
\hline \multirow[t]{2}{*}{ waist-to-hip ratio } & normal & 74 & 21.64 & 53 & 15.50 & 4.492 & 0.034 \\
\hline & abnormal & 268 & 78.36 & 289 & 84.50 & & \\
\hline \multirow[t]{5}{*}{ blood type } & $A B$ & 41 & 11.99 & 33 & 9.65 & 3.523 & 0.620 \\
\hline & $A$ & 52 & 15.20 & 57 & 16.67 & & \\
\hline & B & 49 & 14.33 & 55 & 16.08 & & \\
\hline & $\mathrm{O}$ & 65 & 19.01 & 72 & 21.05 & & \\
\hline & unknown & 135 & 39.47 & 125 & 36.55 & & \\
\hline \multirow[t]{4}{*}{ occupation } & physical labor & 154 & 45.03 & 152 & 44.44 & 12.197 & 0.016 \\
\hline & mental work & 90 & 26.32 & 71 & 20.76 & & \\
\hline & freelance & 26 & 7.60 & 17 & 4.97 & & \\
\hline & no job & 72 & 21.05 & 102 & 29.82 & & \\
\hline \multirow[t]{4}{*}{ work/life pressure } & no & 217 & 63.45 & 222 & 64.91 & 3.08 & 0.544 \\
\hline & little & 96 & 28.07 & 85 & 24.85 & & \\
\hline & more & 23 & 6.73 & 24 & 7.02 & & \\
\hline & great & 6 & 1.75 & 10 & 2.92 & & \\
\hline \multirow[t]{4}{*}{ Living environmental noise } & no & 231 & 67.54 & 223 & 65.20 & 3.22 & 0.521 \\
\hline & little & 85 & 24.85 & 89 & 26.02 & & \\
\hline & more & 21 & 6.14 & 27 & 7.89 & & \\
\hline & great & 5 & 1.46 & 3 & 0.88 & & \\
\hline \multirow[t]{3}{*}{ Personal taste } & salty & 65 & 19.01 & 88 & 25.73 & 5.738 & 0.057 \\
\hline & light & 104 & 30.41 & 110 & 32.16 & & \\
\hline & balance & 172 & 50.29 & 146 & 42.69 & & \\
\hline \multirow[t]{3}{*}{ sleeping time } & inadequate & 43 & 12.57 & 35 & 10.23 & 6.998 & 0.072 \\
\hline & satisfy & 31 & 9.06 & 49 & 14.33 & & \\
\hline & sufficient & 268 & 78.36 & 258 & 75.44 & & \\
\hline \multirow[t]{3}{*}{ Sports habit } & never & 64 & 18.71 & 65 & 19.01 & 1.454 & 0.483 \\
\hline & occasionally & 116 & 33.92 & 129 & 37.72 & & \\
\hline & regular & 162 & 47.37 & 148 & 43.27 & & \\
\hline \multirow[t]{2}{*}{ drinking behavior } & never & 236 & 69.01 & 251 & 73.39 & 2.068 & 0.558 \\
\hline & occasionally & 65 & 19.01 & 59 & 17.25 & & \\
\hline
\end{tabular}


Table 2 Distribution of categorical variables in participants in two groups ( $N, \%$ ) (Continued)

\begin{tabular}{|c|c|c|c|c|c|c|c|}
\hline & & \multicolumn{2}{|c|}{ control group $(n=342)$} & \multicolumn{2}{|c|}{ case group $(n=342)$} & \multirow[b]{2}{*}{$x^{2}$} & \multirow[b]{2}{*}{$\mathrm{p}$} \\
\hline & & $\mathrm{n}$ & $\%$ & $\mathrm{n}$ & $\%$ & & \\
\hline & often & 38 & 11.11 & 33 & 9.65 & & \\
\hline \multirow[t]{4}{*}{ smoking behavior } & never & 225 & 65.79 & 219 & 64.04 & 6.544 & 0.087 \\
\hline & Quit now & 22 & 6.43 & 40 & 11.70 & & \\
\hline & occasionally & 20 & 5.85 & 24 & 7.02 & & \\
\hline & always & 72 & 21.05 & 61 & 17.84 & & \\
\hline
\end{tabular}

(95\% CI: 1.66 11.88), attributable proportion due to interaction (AP) is $43.87 \%$ (95\% CI: 12.84 91.88\%), and the percentage of the interaction between the pure factor (PAP) is $47.55 \%$ (95\%CI: 13.91 99.58\%). The result of AP indicates that $43.87 \%$ of hypertension was attributable to the interaction of them, when exposed to both $\mathrm{FH}$ and BMI risk factors.

\section{Discussion}

Previous studies have shown that hypertension has obvious familial clustering and the family history of hypertension has a heritability of $60 \%$, more than a half of the objects in these studies have family history of hypertension. Compared with patients without family history of hypertension, patients with a family history of hypertension have a lower onset age and higher blood pressure levels, and it indicating that genetic factors can lead to elevated blood pressure levels and advanced onset age $[20,21]$. FH of hypertension is an important marker of genetic factors. In this study, there are $76.17 \%$ of participants have family history of hypertension, and the effect of $\mathrm{FH}$ are significant between case group and control group; The OR of FH on hypertension is 4.986 (95\% CI: $2.832 \sim 8.877$ ), it is clearly showed that FH is an important risk factor of hypertension.

As BMI is a weight-for-height measure, it does not distinguish between fat mass and lean mass [22]. A cross-sectional study in the United States reported a significantly higher risk for elevated BP in the participants with high BMI [23]; In another study, BMI was significantly associated with an increased risk of prehypertension [24]; The current study showed the importance of the interactions of different anthropometric indicators of obesity in assessing the risk of hypertension; overweight/ obesity can assess cardiovascular risk in children and adolescents $[25,26]$. Obesity is a risk factor for the development of hypertension, which can increase hypertension through multiple mechanisms, including insulin resistance, activation of sympathetic nervous system, sodium retention leading to increased renal reabsorption and activation of the renin-angiotensin system [27-30]. The increasing populations of overweight and obese residents

Table 3 The logistic regression analysis results of investigated risk factors on hypertension

\begin{tabular}{|c|c|c|c|c|c|c|c|c|}
\hline \multirow[t]{2}{*}{ Variables } & \multirow[t]{2}{*}{$B$} & \multirow[t]{2}{*}{ S.E, } & \multirow[t]{2}{*}{ Wals } & \multirow[t]{2}{*}{ df } & \multirow[t]{2}{*}{ Sig. } & \multirow[t]{2}{*}{ OR } & \multicolumn{2}{|c|}{ OR 95\% C.I. } \\
\hline & & & & & & & lower & upper \\
\hline Age & -0.255 & 0.205 & 1.551 & 1 & 0.213 & 0.775 & 0.519 & 1.157 \\
\hline Education & 0.091 & 0.103 & 0.791 & 1 & 0.374 & 1.096 & 0.896 & 1.339 \\
\hline BMl & -0.843 & 0.143 & 34.893 & 1 & $<0.001$ & 1.430 & 1.325 & 1.569 \\
\hline WHR & -0.561 & 0.247 & 5.148 & 1 & 0.023 & 1.571 & 1.352 & 1.926 \\
\hline Blood type & -0.006 & 0.066 & 0.008 & 1 & 0.927 & 0.994 & 0.874 & 1.131 \\
\hline Occupation & -0.096 & 0.078 & 1.502 & 1 & 0.220 & 0.909 & 0.780 & 1.059 \\
\hline work/life pressure & 0.156 & 0.155 & 1.023 & 1 & 0.312 & 1.169 & 0.864 & 1.583 \\
\hline environmental noise & -0.057 & 0.145 & 0.154 & 1 & 0.695 & 0.945 & 0.711 & 1.255 \\
\hline Taste & 0.228 & 0.121 & 3.558 & 1 & 0.059 & 1.256 & 0.991 & 1.593 \\
\hline Sleeping time & -0.260 & 0.142 & 3.344 & 1 & 0.067 & 0.771 & 0.584 & 1.019 \\
\hline Sports & 0.090 & 0.125 & 0.512 & 1 & 0.474 & 1.094 & 0.856 & 1.398 \\
\hline Drinking & 0.330 & 0.163 & 4.093 & 1 & 0.048 & 1.391 & 1.010 & 1.914 \\
\hline Smoking & -0.080 & 0.09 & 0.788 & 1 & 0.375 & 0.924 & 0.775 & 1.101 \\
\hline Family history & 1.412 & 0.221 & 40.733 & 1 & $<0.001$ & 4.103 & 2.660 & 6.33 \\
\hline constant & 2.234 & 1.119 & 3.986 & 1 & 0.046 & 9.334 & & \\
\hline
\end{tabular}


Table 4 The multilevel logistic regression analysis results of $\mathrm{FH}$ and $\mathrm{BMI}$ on hypertension

\begin{tabular}{|c|c|c|c|c|c|c|c|c|c|}
\hline \multicolumn{2}{|c|}{ Variables } & \multirow[t]{2}{*}{ B } & \multirow[t]{2}{*}{ S.E, } & \multirow[t]{2}{*}{ Wals } & \multirow[t]{2}{*}{$d f$} & \multirow[t]{2}{*}{ Sig. } & \multirow[t]{2}{*}{$\mathrm{OR}$} & \multicolumn{2}{|c|}{ OR 95\% C.I. } \\
\hline & & & & & & & & lower & upper \\
\hline $\mathrm{FH}$ & Yes & 1.425 & 0.205 & 48.234 & 1 & $<0.001$ & 4.986 & 2.832 & 8.877 \\
\hline \multirow[t]{4}{*}{ BMI } & & & & 63.098 & 3 & $<0.001$ & & & \\
\hline & $<18.5$ & 0.424 & 0.521 & 6.620 & 1 & 0.046 & 1.528 & 0.551 & 4.239 \\
\hline & $24.0 \sim 27.9$ & 1.204 & 0.291 & 17.092 & 1 & $<0.001$ & 3.333 & 1.679 & 6.617 \\
\hline & $\geq 28.0$ & 1.989 & 0.368 & 29.260 & 1 & $<0.001$ & 7.312 & 3.556 & 15.035 \\
\hline
\end{tabular}

$\mathrm{FH}$ family history of hypertension, $\mathrm{BMI}$ body mass index

suggest the potential risk of increasing incidence of hypertension [31]. The population of overweight and obesity may even be under- estimated because the standard definitions for overweight and obesity used in research may be too high for Asian population [32, 33]. Moreover, abdominal obesity can be present in individuals with normal BMI values $\left(18.5-24.9 \mathrm{~kg} / \mathrm{m}^{2}\right)$, and some studies have indicated that this condition could be a risk factor for hypertension [34,35]. Due to the small relatively size of human bodies in Asia, fat usually tends to accumulate in the abdomen, forming central obesity, and central obesity can lead to chronic non-communicable diseases [36-39].

This study shows that the difference of mean weight and BMI between case group and control group is significant $(p<0.001)$, the mean of BMI and weight in case group are significantly higher than that of control group. The difference of BMI effect between two groups is significant $(p<0.05)$, the OR of low weight $(\mathrm{BMI}<18.5)$ is 1.528 , OR of overweight (BMI 18.5 23.9) is 3.333, OR of obesity $(\mathrm{BMI} \geq 24.0)$ is 7.312 . The OR of interaction between $\mathrm{FH}$ and $\mathrm{BMI}$ to hypertension is 12.993 (95\% CI: 7.426 22.734). $\mathrm{OR}_{\mathrm{FH}+\mathrm{BMI}}>\mathrm{OR}_{\mathrm{FH}}+\mathrm{OR}_{\mathrm{BMI}}$, the interaction is greater than the sum of two independent actions, it is showed that $\mathrm{FH}$ and BMI have positive interaction with hypertension.

There are many factors affecting the incidence of hypertension, such as hereditary factors and acquired factors. There are many ways of interactions among these factors. Synergistic effect index (SI), relative excess risk due to interaction (RERI), attributable proportion due to interaction (AP) and the percentage of the interaction between the pure factor (PAP) were used to quantitatively measure

Table 5 The interaction between FH and BMI to hypertension

\begin{tabular}{llllll}
\hline FH & BMl & case group & control group & OR & $95 \% \mathrm{Cl}$ \\
\hline- & - & 20 & 75 & 1.000 & \\
- & + & 32 & 36 & 3.333 & $1.679 \sim 6.617$ \\
+ & - & 117 & 88 & 4.986 & 2.832 8.777 \\
+ & + & 246 & 70 & 12.993 & $7.426 \sim 22.734$ \\
\hline
\end{tabular}

interactions [19, 40, 41]. SI can be used for quantitative and qualitative analysis of interaction. In this study, we quantified interaction by additive model, SI is $1.90(>1)$, it shows that FH and BMI have positive interaction with hypertension. RERI is used for quantitative analysis of interaction, this study shows RERI is 5.67, it shows that interaction between $\mathrm{FH}$ and $\mathrm{BMI}$ is 5.67. AP is used to calculate the proportion attributable to interactions after background effects are removed. This study shows AP is $43.87 \%$, it shows that attributable proportion due to interaction between $\mathrm{FH}$ and $\mathrm{BMI}$ is $43.87 \%$. PAP can explain the degree of harm of exposure factors to a population, and the extent to which these factors may reduce the incidence of disease after elimination, that is the social effects of exposure. This study shows PAP is $47.55 \%$, it shows that the percentage of the interaction between $\mathrm{FH}$ and $\mathrm{BMI}$ is $47.55 \%$. Owing to genetic factors are the factors that cannot be changed, but overweight and obesity are modifiable risk factors, effective proactive intervention programme could help slow and ultimately reduce the number of individuals with obesity becoming hypertensive.

Our study has some limitations. First, the current study explored only by case- control study, and the number of samples is limited. Therefore, our findings need to be confirmed and extended in further larger population and cohort study. The second, in the current study, there was no detailed analysis for WHR, education, blood type, occupation, work and life pressure, environmental noise, taste, sleeping time, sports habit and smoking behavior, for considering that these factors classification are not very elaborate, and it is also not the focus of this study.

\section{Conclusions}

FH and BMI are significant higher risk for hypertension, the risk of hypertension will increase more with the increase of BMI; FH and BMI have positive interaction with hypertension, the interaction is greater than the sum of two independent actions.

\section{Abbreviations \\ BMI: Body mass index; Cl: confidence interval; $\mathrm{FH}$ : family history of hypertension; HC: Hip circumference; OR: odds ratio; WC: Waist circumference; WHR: Waist-to-height ratio}

\section{Acknowledgments}

Thanks their hard work of all doctors, nurses and public health workers in 13 community health service centers in Jiading district in Shanghai China, and thank for some advice of all experts!

\section{Funding}

This study was funded by Jiading district health and family planning commission research project in Shanghai (N0:2016-KY-18).

\section{Availability of data and materials}

The questionnaire and database supporting the conclusions of this article are available, through contact with anle_li@aliyun.com. 


\section{Authors' contributions}

ALL is responsible for the design and implementation of the project, support of project funds, analysis of data and materials, and writing of manuscript; QP and YQS seeks administrative support for projects and assists in the implementation of investigations; XF participates in the project and assists in the investigation; YYZ participates in project investigation and quality control. There is no conflict of interest between us!. All authors read and approved the final manuscript.

\section{Ethics approval and consent to participate}

Ethical approval was granted by Jiading district center for disease control and prevention research ethics committee. All subjects gave verbal and written informed consent to participate in the study, they would like to participate in investigation and answer all the related questions in the questionnaire. The survey was conducted by a full-time investigator using a questionnaire and face-to-face inquiries.

\section{Consent for publication}

Not applicable.

\section{Competing interests}

The authors declare that they have no competing interests.

\section{Publisher's Note}

Springer Nature remains neutral with regard to jurisdictional claims in published maps and institutional affiliations.

\section{Received: 6 December 2018 Accepted: 6 February 2019}

Published online: 21 February 2019

\section{References}

1. Rosner B, Cook NR, Daniels S, Falkner B. Childhood blood pressure trends and risk factors for high blood pressure: the NHANES experience 1988-2008. Hypertension. 2013;62(2):247-54.

2. Delles C, Mcbride MW, Graham D, et al. Genetics of hypertension: from experimental animals to humans [J]. Bio Chim Bio physacta. 2010;1802(12): 1299-308.

3. Liang YJ, Xi B, Hu YH, Wang C, Liu JT, Yan YK, et al. Trends in blood pressure and hypertension among Chinese children and adolescents: China health and nutrition surveys 1991-2004. Blood Press. 2011;20(1):45-53.

4. Zaw KK, Latt TS, Aung PP, et al. Prevalence of hypertension and its associated factors in the adult population in Yangon Division, Myanmar [J]. Asia Pac J Public Health. 2011:23(4):496-506.

5. Center for chronic non communicable diseases control and prevention of China Center for Disease Control and Prevention. Surveillance report of chronic diseases and their risk factors in China (2010) [M].\{H\} Beijing: Military Medical Science Press 2012

6. Levy D, Ehret GB, Rice $K$, et al. Genome-wide association study of blood pressure and hypertension[J]. Nat Genet. 2009:41(6):677-87.

7. International Consortium for Blood Pressure Genome-Wide Association Studies, Ehret GB, Munroe PB, et al. Genetic variants in novel pathways influence blood pressure and cardiovascular disease risk[J]. Nature. 2011; 478(7367):103-9.

8. Kato N, Takeuchi F, Tabara Y, et al. Meta-analysis of genome-wide association studies identifies common variants associated with blood pressure variation in east Asians[J]. Nat Genet. 2011;43(6):531-8.

9. Zhang Y, Shen J, He X, et al. A rare variant at the KYNU gene is associated with kynurenines activity and essential hypertension in the Han Chinese population [J]. Circ Cardiovasc Genet. 2011;4(6):687-94.

10. Rafiq S, Anand S, Roberts R. Genome-wide association studies of hypertension: have they been fruitful? [J]. Cardiovasc Transl Res. 2010;3(3): 189-96.

11. Tadic M, Cuspidi C, Vukomanovic V, et al. The association between obesity, blood pressure variability and right ventricular function and mechanics in hypertensive patients [J]. J AM Soc Echo cardiogr. 2016;29(8):802-11.

12. Tadic M, Cuspidi C, Pencic B, et al. The interaction between blood pressure variability, obesity, and left ventricular mechanics: findings from the hypertensive population[J]. J Hypertens. 2016;34(4):772-80.

13. Manimunda SP, Sugunan AP, Benegal V, Balakrishna N, Rao MV, Pesala KS. Association of hypertension with risk factors \& hypertension related behaviour among the aboriginal Nicobarese tribe living in Car Nicobar Island, India. Indian Journal of Medical Research. 2011:133(3):287-93.

14. Kotchen TA. Obesity-related hypertension: epidemiology, pathophysiology, and clinical management. Am J Hypertens. 2010;23(11):1170-8.

15. Modesti PA, Agostoni P, Agyemang C, et al. Cardiovascular risk assessment in low-resource settings: a consensus document of the European Society of Hypertension Working Group on hypertension and cardiovascular risk in low resource settings. J Hypertens. 2014;32(5):951-60.

16. Millar S, Perry IJ, Phillips CM. Surrogate measures of adiposity and cardiometabolic risk - why the uncertainty? A review of recent meta-analytic studies. J Diabetes Metab. 2013;S11-004:1-11.

17. International Life Science Society China office, China Obesity Task Force, joint data analysis and collaboration group. A brief introduction to the recommendation of Chinese adult body mass index classification [J]. Chin J Prev Med. 2001:35(5):349-50.

18. Ma Xiao-jing, Bao Yu-qian, Jia Wei-ping. The criteria of central obesity in Chinese and the prevention and treatment of cardiovascular disease [M]. Proceedings of the eighth Beijing International Conference on cardiovascular diseases. 2014:132.

19. Zhongtang Zhao. Epidemiological Research Methods and Applications (2nd Edition) [B]. Science Press (Beijing). 2005.8.

20. Liu $M, H e ~ Y$, Jiang $B$, et al. Association between family history and hypertension among Chinese elderly[J]. Medicine. 2015;94(48):e2226.

21. Dong-xia L, Qi H, Jin-cheng G, et al. Investigation and analysis of the characteristics and risk factors of hypertensive patients with family history and without family history [J]. Journal of cardiovascular and cerebrovascular diseases. 2006;25(2):71-4

22. Stein CJ, Colditz GA. The epidemic of obesity. J Clin Endocrinol Metab. 2004 89(6):2522-5.

23. Nafiu OO, Zepeda A, Curcio C, Prasad Y. Association of neck circumference and obesity status with elevated blood pressure in children[J]. J Hum Hypertens. 2014;28:263-8.

24. Guo X, Li Y, Sun G, Yang Y, Zheng L, Zhang X, et al. Prehypertension in children and adolescents: association with body weight and neck circumference. Intern Med. 2012;51(1):23-7.

25. Lu X, Shi P, Luo CY, Zhou YF, Yu HT, Guo CY, et al. Prevalence of hypertension in overweight and obese children from a large school-based population in Shanghai [J]. China BMC Public Health. 2013;13:24.

26. Hu YH, Reilly KH, Liang YJ, Xi B, Liu JT, Xu DJ, et al. Increase in body mass index, waist circumference and waist-to-height ratio is associated with high blood pressure in children and adolescents in China [J]. J Int Med Res. 2011; 39(1):23-32

27. Crump C, Sundquist J, Winkleby MA, et al. Interactive effects of physical fitness and body mass index on the risk of hypertension [J]. JAMA Intern Med. 2016:176:210-6.

28. Papathanasiou G, Zerva E, Zacharis I, et al. Association of high blood pressure with body mass index, smoking and physical activity in healthy young adults [J]. Open Cardiovasc Med J. 2015;9:5-17.

29. Tyson CC, Appel L, Vollmer WM, et al. Impact of 5-year weight change on blood pressure: results from the weight loss maintenance trial [J]. J Clin Hypertens. 2013;15:458-64.

30. Rahmouni K, Correia ML, Haynes WG, et al. Obesity-associated hypertension: new insights into mechanisms [J]. Hypertension. 2005;45:9-14.

31. Yang G, Ma Y, Wang S, et al. Prevalence and correlates of prehypertension and hypertension among adults in northeastern China: a cross-sectional study [J]. Int J Environ Res Public Health. 2015;13:82.

32. World Health Organization. The Asia-Pacific perspective: redefining obesity and its treatment. Sydney: Health Communications Australia; 2000.

33. Anuurad E, Shiwaku K, Nogi A, et al. The new BMl criteria for asians by the regional office for the western pacific region of $\mathrm{WHO}$ are suitable for screening of overweight to prevent metabolic syndrome in elder Japanese workers. J Occup Health. 2003:45:335-43.

34. Okosun IS, Prewitt TE, Cooper RS. Abdominal obesity in the United States: prevalence and attributable risk of hypertension. J Hum Hypertens. 1999;13: 425-30

35. Bergman RN, Kim SP, Hsu IR, et al. Abdominal obesity: role in the pathophysiology of metabolic disease and cardiovascular risk. Am J Med. 2007;120:S3-8.

36. Macumber IR, Weiss NS, Halbach SM, et al. The association of pediatric obesity with nocturnal non-dipping on 24-hour ambulatory blood pressure monitoring [ J]. Am J Hypertens. 2016;29(5):647-52. 
37. Olack B, Wabwire-Mangen F, Smeeth $L$, et al. Risk factors of hypertension among adults aged 35-64 years living in an urban slum Nairobi, Kenya[J]. BMC Public Health. 2015;15(1):1.

38. JOshi MD, Ayah R, Njau EK, et al. Prevalence of hypertension and associated cardiovascular risk factors in an urban slum in Nairobi, Kenya: A populationbased survey[]]. BMC Public Health. 2014;14(1):1.

39. Aune D, Sen A, Norat T, et al. Body mass index, abdominal fatness, and heart failure incidence and mortality: a systematic review and doseresponse meta-analysis of prospective studies []]. Circulation. 2016;133(7): 639-49.

40. Wen-Chung Lee. Assessing causal mechanistic interactions: A Peril Ratio Index of Synergy Based on Multiplicativity [J]. PLoS one. 2013, 8,6: e67424.

41. Dahlqwist E, Pawitan Y, Sjölander A. Regression standardization and attributable fraction estimation with between-within frailty models for clustered survival data. Stat Methods Med Res. 2017. [Epub ahead of print]

Ready to submit your research? Choose BMC and benefit from:

- fast, convenient online submission

- thorough peer review by experienced researchers in your field

- rapid publication on acceptance

- support for research data, including large and complex data types

- gold Open Access which fosters wider collaboration and increased citations

- maximum visibility for your research: over $100 \mathrm{M}$ website views per year

At BMC, research is always in progress.

Learn more biomedcentral.com/submissions 